\title{
Surface Engineering: Applications for Advanced Manufacturing
}

\author{
CHRISTOPHER C. BERNDT (1) ${ }^{1,3}$ and MA QIAN (iD) 2,4 \\ 1.-SEAM: 'Surface Engineering for Advanced Materials', Faculty of Science and Engineering \\ Technology, Swinburne University of Technology, Melbourne, Australia. 2.-Centre for Additive \\ Manufacturing, School of Engineering, RMIT University, Melbourne, Australia. \\ 3.—e-mail: cberndt@swin.edu.au. 4.—e-mail: ma.qian@rmit.edu.au
}

Surface engineering and advanced manufacturing intersect under the umbrella of interface engineering where atomic movement and phase transitions determine physical properties. Controlling the process conditions will determine the structure and, hence, scientists and engineers have strong tools to manufacture artifacts that serve a plethora of industrial and scientific applications. Surface engineering is also related to additive manufacturing in special cases where materials are joined to make parts from a 3D model data in a layer upon layer fashion.

Examples of processes and their applications are presented in this issue that feature additive manufacturing, metal membrane fabrication, surface coatings and thin film plasma technologies. The gamut of contributions includes scientific advancements of Manufacturing Readiness Level (MRL) 35 , as well as technology that has transformed into MRL 6-7 and in several cases adopted by industry (MRL 8-9).

Three manuscripts focus on high temperature applications. Yang et al. present 'Fabrication of industrial-scale porous stainless steel membrane tubes and their applications', where stainless steel membrane tubes $(\Phi 60 \mathrm{~mm} \times 1000 \mathrm{~mm})$ were fabricated from three membrane powders $(4 \mu \mathrm{m}, 12 \mu \mathrm{m}$ and $20 \mu \mathrm{m}$ ) that were wet sprayed onto a presintered stainless steel support tube. Darcy's Law was employed to describe the permeability of the assintered stainless steel membranes. The porous 316L membrane tubes have demonstrated remarkable performance in filtering hot gas mixtures of $\mathrm{CO}$ and nickel carbonyl $\left(\mathrm{C}_{4} \mathrm{NiO}_{4}\right)$ in continuous industrial operations.

Christopher Berndt and Ma Qian are JOM Guest Editors for the invited special topic Surface Engineering: Applications for Advanced Manufacturing in this issue.

(Received October 8, 2020; accepted October 12, 2020; published online November 2, 2020)
A second study improved the oxidization and wear resistances of pure Ti and Ti alloys by implementing a packed powder diffusion coating (PPDC) technique. In this study, Zhang et al., 'A novel surface treatment technique for titanium alloys', employed an $\mathrm{Al}_{3} \mathrm{Ti}$ intermetallic based composite coating that varied in thickness from $100 \mu \mathrm{m}$ to $1295 \mu \mathrm{m}$. The PPDC treatment has the potential for these lightweight $\mathrm{Ti}$ alloys to replace $\mathrm{Ni}$-based superalloys in high temperature applications.

The final contribution that addresses high temperature oxidation is by Choi et al., on 'Oxidation behavior of pack-cemented refractory high entropy alloy'. This study fabricated a high entropy alloy by powder metallurgy and aluminum pack cementation performed at $500^{\circ} \mathrm{C}$ and $800{ }^{\circ} \mathrm{C}$ for up to $5 \mathrm{~h}$. The specimen treated at $800^{\circ} \mathrm{C}$ for $5 \mathrm{~h}$ exhibited a superior oxidation resistance compared to both the specimen that was not subjected to pack cementation and the one pack-cemented at $500^{\circ} \mathrm{C}$ for $5 \mathrm{~h}$. The oxidation behavior was interpreted in terms of atomic diffusion.

The following two contributions address thermal spray coatings. The paper by Rashid et al. on 'Plasma sprayed $\mathrm{Al}$ alloy coating with enhanced lamellar bonding through novel self-bonding strategy' examined metallurgical bonding through impact-induced melting. Numerical simulations estimated the interface temperature between superheated molten droplets of $\mathrm{Al}$ splats and the $\mathrm{Al}$ substrate. The interfacial bonding was examined from cross sections of the $\mathrm{Al}$ splat and etched coatings. It was shown that $\mathrm{Al}$ droplets exceeding $1800^{\circ} \mathrm{C}$ exhibited substrate melting that was impact-induced. A companion study by Liao et al. on 'Self-bonding effect development for plasma spraying of stainless steel coating through using Mo-clad stainless steel powders', considered 304SS$17 \mathrm{Mo}$ powders prepared by mechanical alloying that were then plasma sprayed. The ultra-high temperature droplets gave rise to enhanced inter-lamellar bonding. The measurement of in-flight particle 
temperature predicted the creation of a self bonding effect, which was confirmed by microstructural examination and mechanical integrity tests.

Laser cladding is gaining prominence in the surface engineering arena as demonstrated by the next three contributions. Schulz et al., in 'Considering impact and corrosion resistance in the performance of heavy wear resistant coatings', address industries such as mining and transportation. A high velocity oxygen fuel $\mathrm{WC} / \mathrm{CoCr}$ coating and a hard chrome reference coating were tested for their impact and corrosion resistance. The impact resistance was determined by a single impact with a hard, spherical indenter. Corrosion resistance were tested by electrochemical corrosion in a $3.5 \mathrm{wt} . \%$ $\mathrm{NaCl}$ solution and by exposure, for up to $1000 \mathrm{~h}$, in the salt spray test.

The deposition parameters were studied in a study by $\mathrm{Wu}$ et al. on 'Ultra-high-speed laser cladding of Stellite ${ }^{\circledR} 6$ alloy on mild steel'. Ultrahigh-speed laser cladding (UHSLC) refers to metal deposition at speeds above $20 \mathrm{~m} / \mathrm{min}$ or rates of $120 \mathrm{~cm}^{2} / \mathrm{min}$. The effects of the laser energy density $\left(2.56-15.00 \mathrm{~J} / \mathrm{mm}^{2}\right)$ and powder stream focal position relative to the substrate $(0.2-0.8 \mathrm{~mm})$ were investigated for a Stellite ${ }^{\circledR} 6$ coating on a mild steel substrate. Results are presented on how the clad layer thickness and microstructure can be controlled by changing the laser energy density and powder stream focal position.

$\mathrm{Li}$ et al. in their contribution titled 'Commercial scale uniform powder coating for metal additive manufacturing' have identified the feedstock as being a critical parameter. It is challenging to $3 \mathrm{D}$ print high laser-reflectivity metals and metal matrix composites due to loss of laser energy and the lack of high-quality composite powders. Their work reports the commercial scale coating of powder by (1) electroless plating for high laser-reflectivity metals, and (2) fluidized bed chemical vapor deposition (FBCVD) for composite powders. It is demonstrated that coating high laser-absorptivity metals of $\mathrm{Co}$ and $\mathrm{Ni}$ onto $\mathrm{Al}$ powder enhanced 3D printing characteristics and lead to good physical and mechanical properties.

A further two manuscripts push the boundaries of materials processing. Song presents 'Copper surfaces with bimodal nanoporosity by microstructurallength-scale-controlled dealloying of a hypereutectic $\mathrm{Al}-\mathrm{Cu}$ alloy'. Copper surfaces that exhibit bimodal nanoporosity were fabricated by dealloying of an ascast hypereutectic alloy Al75-Cu25 (at.\%) alloy. This alloy solidifies as pre-eutectic $\mathrm{Al}_{2} \mathrm{Cu}$ (micrometrescaled) and a eutectic lamella of $\alpha-\mathrm{Al} / \mathrm{Al}_{2} \mathrm{Cu}$ (nanoscaled). The bimodal nanoporous surface of the copper evolves by a dealloying process that is controlled by the different microstructural scales. In-situ synchrotron XRD data revealed a two stage kinetic process for the formation of bimodal nanoporous $\mathrm{Cu}$ surfaces.

The final contribution of this Special Issue, by Kondoh et al., is titled 'Understanding corrosion behavior of magnesium surface by x-ray irradiation for improved surface design and applications'. The surface is modified by x-ray irradiation in humid air to improve the corrosion resistance of magnesium samples. Hydroxyl radicals generated by water ionization during x-ray irradiation reacted with natural oxide films and resulted in a dense surface film of approximately $50 \mathrm{~nm}$ thickness as protection against corrosion. This surface modification process is environmentally friendly since no hazardous materials are released and the ability to recycle magnesium is enhanced.

This special topic in JOM is 'special' in aspects other than science and engineering. For instance, the authors are from many nations. The guest editors thank these authors and the many reviewers who contributed their expertise and time in producing excellent technical and scientific articles that shed light on future pathways. Their engagement has been rewarding at many levels. The editors are grateful for the administrative support, professional interaction, and encouragement of TMS staff throughout the publishing process.

\section{DEDICATION}

This special topic has been incubated and delivered during a global pandemic. Thus, the guest editors, authors and TMS staff dedicate this special topic to the many health care professionals who have been at the forefront of saving lives. Your courage and self-sacrifice is recognised. You are our "special heroes". Thanks.

The papers in this special topic, Surface Engineering: Applications for Advanced Manufacturing, can be accessed via the December issue's Table of Contents page at https://link.springer.com/journal/ 11837/72/12/page/1.

\section{CONFLICT OF INTEREST}

On behalf of all authors, the corresponding authors state that there is no conflict of interest. Publisher's Note Springer Nature remains neutral with regard to jurisdictional claims in published maps and institutional affiliations.

Publisher's Note Springer Nature remains neutral with regard to jurisdictional claims in published maps and institutional affiliations. 